\title{
Francês on-line na pandemia: memes como ferramenta de ensino-aprendizagem
}

\author{
Online French during the pandemic: memes \\ as a teaching-learning tool
}

\author{
Brenda Balbinotti ${ }^{1}$ \\ Keren Coimbra Fagundes 2 \\ Bruna Brito Soares ${ }^{3}$ \\ Sara Farias da Silva ${ }^{4}$
}

\begin{abstract}
Resumo
Articulando ensino-aprendizagem de Francês Língua Estrangeira (FLE) com as novas tecnologias no cenário da pandemia de Covid-19, pretendemos apresentar neste artigo as (novas) práticas do ensino-aprendizagem do francês com ênfase no perfil do professor de FLE e o uso de memes nas aulas de francês on-line. A motivação para essa pesquisa se deu em razão de duas questões primordiais: o aumento da procura por aulas remotas de FLE e a necessidade do professor de FLE de se reinventar diante do distanciamento social devido à pandemia. A pesquisa qualitativa foi realizada entre março e agosto de 2020 e contou com a aplicação de um questionário on-line, via Google Forms, que teve como objetivo principal realizar um recorte do perfil desse professor de FLE que está trabalhando com o ensino remoto e verificar o uso dos memes como ferramenta de ensino no processo de elaboração dessas aulas. 0 artigo apresenta, portanto, uma reflexão sobre as novas práticas do ensino-aprendizagem de FLE no contexto da pandemia iniciada em 2020.
\end{abstract}

Palavras-chave: Francês On-line. Memes. Covid-19.

\section{Abstract}

Articulating teaching and learning French as a Foreign Language (FFL) with the new technologies in the Covid-19 scenario, we intend to present in this article the (new) practices of teaching and learning French with an emphasis on the profile of the FFL teacher and the use of memes in online French classes. The motivation for this research was due to two main issues: the increased demand for online FFL classes and the need for the FFL teachers to reinvent themselves in the face of social distancing due to the pandemic. The qualitative research was carried out between March and August of 2020 and it included the application of an online questionnaire, via google forms, which its main objective was to make a profile of this FFL teacher who is working with online teaching and to verify the use of memes as a teaching tool in the process of preparing these classes. The article therefore presents a reflection on the new practices of teaching and learning of FFL in the context of the pandemic experienced in 2020 .

Keywords: Online French. Memes. Covid-19.

\footnotetext{
${ }^{1}$ Graduanda Letras - Licenciatura Francês. Universidade Federal de Santa Catarina (Brenda Kieling Balbinotti, Florianópolis, Santa Catarina, Brasil). Orcid: https://orcid.org/0000-0002-5952-8454 E-mail: brendakielingb@gmail.com

${ }^{2}$ Graduanda Letras - Licenciatura Francês. Universidade Federal de Santa Catarina (Keren Coimbra Fagundes, Florianópolis, Santa Catarina, Brasil). Orcid: https://orcid.org/0000-0001-8559-2444 E-mail: kerencoimbra@gmail.com

${ }^{3}$ Doutoranda em Estudos da Tradução (PGET). Universidade Federal de Santa Catarina (Bruna Brito Soares, Florianópolis, Santa Catarina, Brasil). Orcid: https://orcid.org/0000-0003-2842-5732 E-mail: profabrunabrito@gmail.com

${ }^{4}$ Doutora em Linguística. Universidade Federal de Santa Catarina (Sara Farias da Silva, Florianópolis, Santa Catarina, Brasil). Orcid: https://orcid.org/0000-0002-9508-6059 E-mail: foliesara@.gmail.com
}

LínguaTec, Instituto Federal de Educação, Ciência e Tecnologia do Rio Grande do Sul, Bento Gonçalves 


\section{Introdução}

Vivenciando o contexto de distanciamento social causado pela COVID-19, percebemos a necessidade de reinvenção nessa nova realidade que nos é apresentada, partindo do nosso lugar de professoras em (contínua) formação de Francês Língua Estrangeira (FLE) que refletem sobre o ensinoaprendizagem dessa língua. Com a chegada inesperada do vírus, as formas de realizarmos nossas atividades diárias precisaram ser remodeladas, novos protocolos foram sugeridos, entre eles 0 teletrabalho ou trabalho remoto (home office em inglês, télétravail em francês), e, consequentemente, a elaboração de novas práticas sobre o ensino-aprendizagem. Nessa conjuntura, houve um aumento significativo na busca do termo "aula on-line francês", conforme indicam os dados apresentados pela ferramenta Google Trends ${ }^{5}$ - que mostra os mais populares termos buscados em um passado recente. Revela-se, então, que há um perfil de aluno que encontra na tecnologia uma solução para continuar os estudos, apesar da necessidade de manter a distância social. Simultaneamente, percebemos um aumento na procura de termos relacionados a "como dar aula on-line" e de quais plataformas usar nessa modalidade. Nota-se, portanto, um possível perfil de professores de FLE que, atentos a essa nova dinâmica de ensino-aprendizagem, tiveram de migrar para a modalidade de ensino remoto. Esse perfil será melhor apresentado na seção 2 deste artigo.

Nesse sentido, o questionamento é se o ensino on-line influencia na didática e metodologia utilizada pelo professor. Há uma absorção da cultura da internet ou esta é utilizada apenas como ferramenta de comunicação? Para responder nossos questionamentos, organizamos o artigo da seguinte forma: o primeiro momento diz respeito ao francês no Brasil e seu ensino; em seguida, realizamos um levantamento teórico sobre o uso da internet pelos brasileiros e sobre a utilização de memes como ferramenta no ensino de língua estrangeira; para então discutirmos os resultados do formulário intitulado "O FLE em tempos de Likes", realizado via Google Forms, a fim de verificar o perfil do professor de FLE, sua relação com o ensino-aprendizagem on-line e a utilização de memes em sua - nova - prática didática.

\section{Francês no Brasil}

Desde antes de 1800, o francês foi se estabelecendo no Brasil devido a mudanças culturais e políticas. Souza e Souza (2012) afirmam que entre as propostas da Reforma Pombalina do século XVIII,

\footnotetext{
${ }^{5}$ Para mais informações acesse: https://trends.google.com.br/trends/?geo=BR.
} 
as línguas vivas, incluindo o francês, tiveram espaço no ensino, que até então tinha ênfase em línguas clássicas. Nessa perspectiva, podemos compreender que a língua francesa participou da construção social, educacional e econômica do país. Foram essas mudanças que a levaram a ser a língua da diplomacia no século XVIII e a ter seu auge no Brasil durante a Era Vargas, em 1942 (ARRUDA, 2016).

Segundo a Organisation Internationale de la Francophonie (2019), atualmente, o ensino do Francês Língua Estrangeira (FLE) atinge todos os continentes, sendo o francês a quinta língua mais falada no mundo. A globalização permitiu o crescimento do intercâmbio entre as universidades brasileiras e francófonas ${ }^{6}$, tornando o francês relevante para a academia e para o mercado mundial. Nesse contexto, a cibercultura, proposta por Pierre Lévy nos anos 1990, possibilita, por meio das Tecnologias da Informação e Comunicação (TICs), uma interconexão cultural, linguística e social entre as pessoas de todo o mundo. A partir de então, o modo de ensino está sendo desconstruído ao passo que um novo espaço de ensino-aprendizagem vem sendo formado, ainda conforme 0 autor:

\begin{abstract}
O que é preciso aprender não pode mais ser planejado nem precisamente definido com antecedência. [...] Devemos construir novos modelos do espaço dos conhecimentos. No lugar de representação em escalas lineares e paralelas, em pirâmides estruturadas em 'níveis', organizadas pela noção de pré-requisitos e convergindo para saberes 'superiores', a partir de agora devemos preferir a imagem em espaços de conhecimentos emergentes, abertos, contínuos, em fluxo, não lineares, se reorganizando de acordo com os objetivos ou os contextos, nos quais cada um ocupa posição singular e evolutiva. (LÉVY, 1999, p. 158).
\end{abstract}

De acordo com a professora Raquel Fellet (2020), com o advento das Novas Tecnologias de Informação e Comunicação (NTIC), no contexto da Revolução Informacional e da Web 2.0, surgem novos modelos para o ensino de línguas estrangeiras, mediados pelas plataformas digitais. Ainda segundo a professora, é importante que haja uma "reflexão sobre as vantagens e desvantagens que essas novas tecnologias trazem para atender às necessidades dos diferentes perfis de aluno" (FELLET, 2020, p. 1), visto que cada aluno apresenta uma demanda singular de ensino-aprendizagem, tendo como objetivo aprender uma língua estrangeira voltada ao universo acadêmico, profissional ou de interesses outros.

Dessa forma, a cibercultura promoveu recursos e ferramentas tecnológicas essenciais para propagar o conhecimento, ensinar, aprender e se comunicar. Esse novo período trouxe para o ensino de língua novos desafios, levando o professor de língua estrangeira a reinventar suas práticas de ensino para uma prática mais integrativa e dinâmica com o mundo virtual.

\footnotetext{
${ }^{6}$ A Secretaria de Relações Internacionais (SINTER) da Universidade Federal de Santa Catarina (UFSC) viabiliza a mobilidade da comunidade universitária entre a UFSC e universidades francófonas através de programas, tais como Bolsa de Estudos ELAP (Canadá), Programa Outgoing, USAC etc.
} 


\section{Uso da internet pelos brasileiros}

Sobre a relação do uso da internet pelos brasileiros, um estudo (SILVA, 2019) realizado em uma parceria da Hootsuite com a We Are Social apresenta o Brasil sendo o segundo país do mundo que passa mais tempo conectado à internet. Enquanto os outros países do mundo passam o correspondente a cem dias do ano conectados, no Brasil gastam-se 45 dias a mais em comparação com as outras nações, o que corresponde a seis horas diárias ao redor do mundo e nove horas e vinte minutos por dia entre os usuários brasileiros. Ainda sobre essa questão, em 2018, o IBGE indicou que dois terços da população do país $(69,8 \%)$ já possuíam conexão com a internet. Esse dado deve ser levado em consideração, uma vez que tal uso por parte dos brasileiros aumentou em 112\% em comparação com 0 mesmo período do ano passado, como indica Akamai $(2020)^{7}$, a maior plataforma de armazenamento em nuvem. Além disso, segundo os dados da Anatel (2020), foi observado um aumento entre 40\% e $50 \%$ do uso da internet nesse período da pandemia, sendo possível questionar, então, se houve um aumento também da procura em aprender uma língua estrangeira on-line por parte dos brasileiros.

A título de ilustração, podemos citar a reportagem sobre a ascensão milionária de novos inscritos na plataforma de ensino-aprendizagem de línguas estrangeiras chamada DUOLINGO8 (APRÍGIO, 2020). Esse aplicativo permite ao usuário-aluno conhecer e praticar algumas competências linguísticas da língua-alvo e realizar atividades em vários níveis de aprendizagem. Nos dados de pesquisa organizados e disponibilizados pelo Google Trends, é possível verificar esse aumento em relação à busca pelo termo "aula on-line francês". Os dados oferecidos por essa ferramenta nos indicam que a procura pelo aprendizado de línguas estrangeiras, sendo o francês uma delas, cresceu exponencialmente com 0 começo da quarentena no Brasil, como nos mostra o Gráfico 1 a seguir:

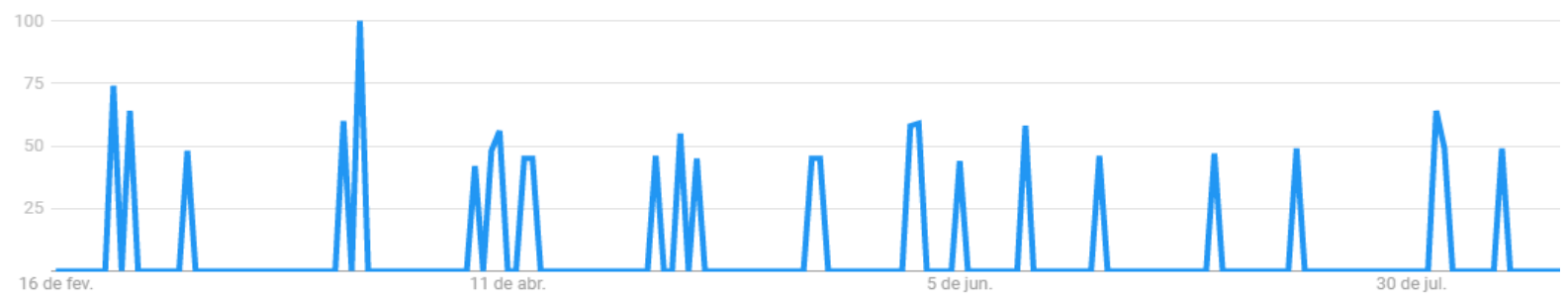

Gráfico 1. Pesquisas realizadas na Google por "aula on-line francês".

Fonte: adaptado de Google Trends (2020).

\footnotetext{
${ }^{7}$ Akamai é uma plataforma que oferece armazenamento em nuvem, serviços CDN (Rede de Entrega de Conteúdo) para entrega de mídia e software, e segurança para aplicações empresariais. Para mais informações acesse: https://www.akamai.com/br/pt/.

${ }_{8}$ Para mais informações acesse: https://pt.duolingo.com/.
} 
O artigo de Xavier, Souza e Oliveira (2019, p. 144) chama a atenção para o fato de que o Brasil se apresenta "como uma das comunidades mais participativas da internet", presença esta que é caracterizada por seu caráter cômico e irônico, geralmente em forma de memes. Como exemplo desse tipo de manifestação, temos as três "Guerras Memeais", citadas pela revista Galileu (2016) e pelo HuffPost Brasil (2016), que ocorreu em 2016, no Twitter. Essa guerra consistiu na disputa dos direitos autorais de determinados memes entre, primeiramente, o Brasil e Portugal e, em seguida, entre o Brasil e a Argentina, finalizando com a "Terceira Guerra Memeal" entre Brasil e Espanha (MOREIRA, 2016). Os brasileiros alegavam que os portugueses haviam roubado seus memes. Na época da guerra de memes, a hashtag "BR x PT" (\#BRxPT) subiu aos trending topics ${ }^{9}$ do Twitter, rede social utilizada como campo de batalha.

Além desse caso em que os brasileiros se mobilizaram em prol dos memes nacionais, também há 0 caso da cantora e figura pública Gretchen ${ }^{10}$, considerada a rainha dos memes. Devido à força da presença dos brasileiros na internet, seu reconhecimento se tornou internacional e chegou a ser convidada pela cantora norte-americana Katy Perry para fazer parte de um de seus clipes, conforme divulgado pelo portal de notícias on-line R7, em 201911.

Nota-se que a produção e o consumo de memes fazem parte da rotina dos usuários brasileiros e são uma característica de suas manifestações nas redes sociais. Nesse sentido questionamos: qual seria o perfil do professor de FLE on-line? E como seria a relação desse professor com a elaboração de suas aulas e com o uso de memes nesse cenário que implica, obrigatoriamente, aulas remotas? Essas questões serão discutidas na seção 4, logo após conceituarmos o termo "meme" e sua relação com o ensino-aprendizagem.

\section{Afinal, o que seria um meme?}

Podemos definir meme como um gênero emergente da internet que surge e se dissemina rapidamente, e que abarca múltiplas facetas ao mesclar texto escrito e imagens, possibilitando uma ampla gama de interpretações. As compreensões advindas dele vão, conforme Lucena e Pontes (2018, p. 95), "desde o foco temático ao qual o contexto foi estruturado até às depreensões expressas pelos sujeitos sociais no processo de leitura", uma vez que o leitor precisa ser capaz de ler e compreender não apenas o texto que lhe é apresentado, mas também a imagem que lhe é proposta. De acordo com

\footnotetext{
9 Trending topics é uma lista de temas mais citados no Twitter durante determinado período.

${ }^{10}$ Nascida Maria Odete Brito de Miranda, é uma cantora e empresária brasileira que vendeu cerca de 15 milhões de discos durante quase quarenta anos de carreira. Ficou muito conhecida após postar vídeos falando francês no Youtube.

${ }^{11}$ Disponível no site: Saiu! Katy Perry divulga clipe estrelado por Gretchen.
} 
Hemais (2015 apud CARDOSO; ALCÂNTARA; MATTA, 2019, p. 65), nos memes "o verbal e o visual se complementam, e potencializam os efeitos de sentido para o leitor".

Um elemento característico do meme é sua alta capacidade de se moldar, de se encaixar em diversas situações. Xavier, Souza e Oliveira (2019, p. 143) acreditam que:

\begin{abstract}
Em contextos de produção de textos, ele ganha a dimensão de um gênero textual híbrido em que a imagem e 0 texto se completam. Enquanto gênero, os memes possuem uma alta capacidade de replicação de ideias e são altamente dinâmicos e efêmeros. Sempre que uma determinada ideia, conceito, cena ou acontecimento atinge relevância social, pode-se criar um meme que pode ser compartilhado e alterado infinitas vezes.
\end{abstract}

Ainda sobre a estrutura desse gênero, o caráter híbrido do meme ou, conforme os autores Cardoso, Alcântara e Matta (2019, p. 65), "sua plasticidade [...] permite que usuários modifiquem, criem e recategorizem os memes em diferentes semioses. [...] memes podem ser (e, de fato, o são) textos multimodais". Eles são, portanto, um "artefato cultural e textual do ambiente virtual, elementos que nas redes sociais transportam informações e carregam ideias, emoções, argumentos e pontos de vista, configurando-se de maneira diferenciada e se consolidando como gênero" (LIMA; CASTRO, 2016 apud CARDOSO; ALCÂNTARA; MATTA, 2019, p. 64), contribuindo no processo de elaboração das aulas online e sendo, consequentemente, uma ferramenta interessante no uso do ensino-aprendizagem de FLE.

Também observamos o caráter humorístico e, muitas vezes, irônico que a criação de um meme oferece aos seus leitores. Segundo Barreto (2015), o humor pode servir como uma forma de criticar o mundo real ao sugerir uma perspectiva alternativa desse real e, uma vez que ele é construído de forma ambígua, "ele acaba servindo às mais diversas funções conversacionais, além de fazer as pessoas rirem" (BARRETO, 2015, p. 86). À vista disso, seguimos nossa construção de saber, compreendendo que o meme, além de ter esse caráter humorístico e híbrido, permite um acesso às questões culturais que permeiam as práticas linguísticas e sociais dos sujeitos.

No Brasil, podemos citar os memes que viralizaram com as artistas brasileiras Inês Brasil ${ }^{12} \mathrm{e}$ Gretchen e com o cozinheiro francês e jurado do programa Master Chef, Érick Jacquin ${ }^{13}$. Essas figuras públicas têm seus memes traduzidos e postados constantemente nas redes sociais, alimentando uma gama substancial desse gênero híbrido e humorístico, possibilitando considerá-lo também um gêneroparódia. Percebemos, assim, os memes como mensagens vinculadas a imagens autoexplicativas e que pertencem ao imaginário coletivo de uma determinada comunidade ${ }^{14}$.

\footnotetext{
12 Inês Tânia Lima da Silva é uma cantora, compositora e dançarina brasileira.

13 Érick Jacquin é um chef de cozinha francês, conhecido no Brasil por atuar como jurado no programa Master Chef.

${ }^{14}$ Alguns dos memes que mais viralizaram no Brasil e que são reflexos de pensamentos e questões comuns da sociedade brasileira como "um cachorro, me segura que eu vou adotar", "quando cai o salário do mês" podem ser acessados através
} 
Outro aspecto que pudemos verificar é que, diferentemente de outras imagens e textos divulgados, os memes tendem a não mencionar o nome do criador, transformando-se em algo "pertencente à internet", à comunidade, e não mais a um único autor, pois, conforme Xavier, Souza e Oliveira (2019, p. 152), "ele é rapidamente readaptado, servindo de base para paródias", ou seja, carrega consigo a possibilidade de infinitas recriações.

Ao produzir, adaptar e compartilhar memes, os internautas assumem o papel de produtores do seu próprio entretenimento, tendo, assim, um papel ativo nesse processo. No contexto do ensinoaprendizagem, é importante que essa agentividade da parte do aluno seja estimulada, nesse sentido, o uso dos memes na elaboração das aulas torna-se uma ferramenta que possibilita uma dinâmica potencializadora da construção de saber do aluno em relação à língua que ele está aprendendo.

Segundo o empresário e responsável por diversos sites de humor, Ben Huh ${ }^{15}$, o sucesso de seus sites de humor se deve ao fato de que, ao produzirem e compartilharem conteúdos humorísticos, os internautas sentem prazer em participar ativamente da produção desse tipo de conteúdo (ARAÚJO, 2012, p. 29-30), fugindo, assim, da lógica de um consumidor/leitor passivo. Lucena e Pontes (2018, p. 102) discutem o caráter maleável do meme, bem como o papel ativo dos sujeitos em relação a ele:

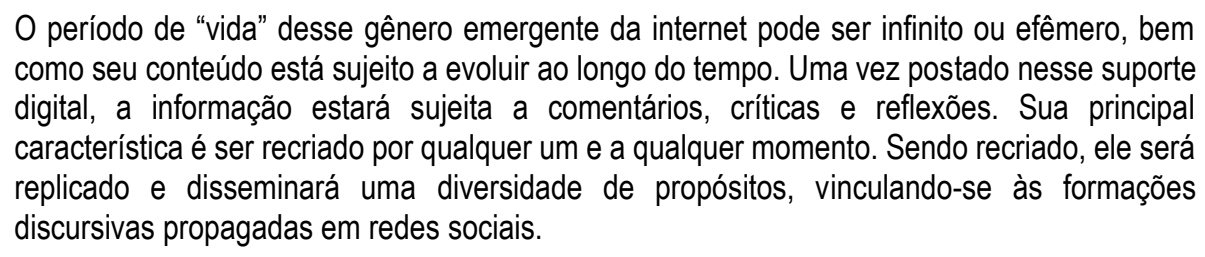

Atentamos ainda que o uso e a criação de memes é algo das novas gerações, fazendo parte de uma cultura de pessoas mais jovens que tiveram mais acesso ao letramento digital. Dessa maneira, a maior parte dos assuntos propostos, ou das figuras públicas escolhidas, é mais relacionada à atualidade, ainda que temas e personagens do passado sejam referenciados.

Após elucidar nossas observações sobre o meme no espaço cibercultural, vamos agora relacionar essa ferramenta híbrida, humorística, por vezes irônica e repleta de paródias, com o ensinoaprendizagem de FLE.

dos sites, respectivamente https://capricho.abril.com.br/wp-content/uploads/2016/07/et-1061761.jpg?quality=70\&strip=all e https://recordtv.r7.com/programa-do-porchat/fotos/rainha-da-internet-gretchen-cria-os-melhores-memes-no-programa-doporchat-21102018\#next

${ }^{15}$ Ben Huh é um empresário sul-coreano-americano da internet, responsável pela maior rede de criação e compartilhamento de humor, incluindo memes.

LínguaTec, Instituto Federal de Educação, Ciência e Tecnologia do Rio Grande do Sul, Bento Gonçalves v. 6, n. 2, p. 53-69, jun. 2021. 


\section{0 meme como ferramenta no ensino-aprendizagem de FLE}

Neste momento, retomamos nossa questão inicial sobre o ensino remoto e sua possível influência na didática e na metodologia utilizada pelo professor. Conforme já mencionado, o uso da internet pelos brasileiros se multiplicou, e a procura por aprender uma língua estrangeira se intensificou. Sendo assim, a relação entre memes e ensino-aprendizagem de FLE é um tema que nos atravessa enquanto professoras de francês e que faz parte de nossa prática didática.

Por ser uma ferramenta que permite a reflexão sobre contextos culturais, políticos e sociais - e até gramaticais, o meme é um ótimo recurso para ser aplicado em nossas aulas. Podemos utilizar como exemplo o meme sobre queimar carros na França, representado na Figura 1. Por meio dele, podemos analisar as frases nos mais diversos níveis linguísticos, sintática, morfológica e visualmente, além de explicar a cultura de fortes protestos na França e o porquê dessa historicidade.

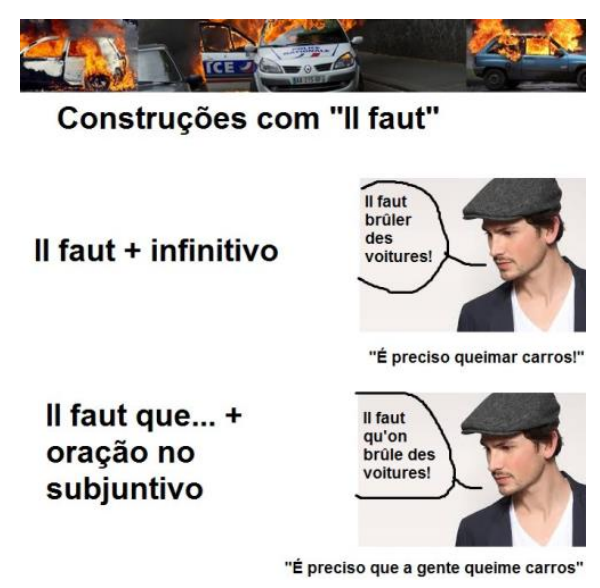

Figura 1. Meme: É preciso queimar carros!

Fonte: Adaptado de WOOSHING (2018).

Sendo assim, conforme os autores Xavier, Souza e Oliveira (2019, p.143) "os memes podem contribuir na manutenção dos estereótipos ou questioná-los", e sua utilização é algo, por conseguinte, muito positiva, visto que o conhecimento prático nos permite esses questionamentos que não surgiriam normalmente, quando aprendemos passivamente, ou seja, quando o ensino está voltado para a figura do professor e não para a relação da aprendizagem tendo o aluno enquanto agente da sua construção de savoir-faire ${ }^{16}$.

Além disso, "quando nós usamos a linguagem, estamos realizando ações individuais e sociais que são manifestações socioculturais, materializadas em gêneros textuais (...)" (DIONÍSIO, 2006, p. 133,

\footnotetext{
${ }^{16}$ Competência adquirida por um conjunto de conhecimentos e experiências relativos à resolução de problemas práticos.
} 
apud LUCENA, 2018, p. 100). Assim, visualizar, compreender e criar um meme nos permite nos identificarmos como grupo social que compartilha de experiências em comum.

O meme é um "replicador de ideias em contexto linguístico e digital" (XAVIER; SOUZA; OLIVEIRA, 2019, p. 143), que demanda

criatividade e raciocínio engenhoso para que uma ideia seja resgatada da memória cultural coletiva e seja reapresentada nos memes com distintas roupagens a cada retorno, perpassando a estrutura e chegando na semântica da língua para produzir novos significados. (XAVIER; SOUZA; OLIVEIRA, 2019, p. 144).

Tomemos o exemplo do meme "não sou capaz de opinar". O meme surgiu durante a transmissão do Oscar (2016) na Globo, a partir dos comentários da atriz Glória Pires sobre os filmes indicados, tais como: "não sou capaz de opinar sobre isso" e "não assisti nenhum dos dois". A partir desse meme brasileiro17, a página do Facebook "Memes BR em FR" realizou a tradução da fala da atriz para a língua francesa. A partir desse exemplo, podemos perceber a autonomia que os memes permitem dentro do ensino-aprendizagem. Os brasileiros, estudantes de língua francesa, que já conhecem o meme, ao lê-lo em francês, poderão identificar e aprender estruturas linguísticas através da comparação entre as duas frases. Nesse caso, é possível que o aprendizado seja feito a partir de uma memória visual e escrita. 0 aluno, como já conhece o que a frase quer dizer, poderá aprender a frase em FLE sem necessitar procurar o significado de cada palavra separadamente. Essa interação meme-língua favorece um aprendizado mais autônomo para a construção do seu savoir-faire.

Tal meme permitiu a tradução dos significados das ideias de um certo contexto linguístico e cultural, nesse caso do português brasileiro e dos brasileiros, para um novo contexto, a língua francesa e os franceses. Desta forma, um meme brasileiro é transposto cultural e linguisticamente para um novo formato.

Podemos aprofundar ainda mais essa reflexão por meio da análise do meme representado na Figura 2.

\footnotetext{
${ }^{17}$ Meme disponivel em: $\underline{\text { https://www.facebook.com/MemesBRemFR/. }}$
} 


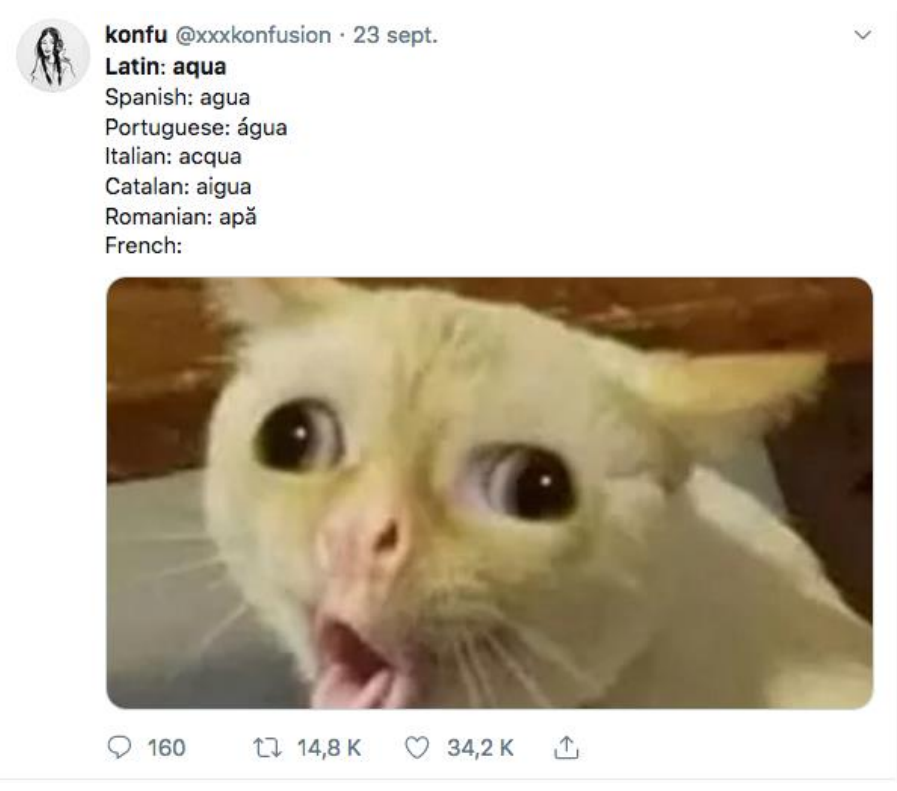

Figura 2. Pronúncia da palavra "água" em francês.

Fonte: Adaptado de KONFU (2020).

O meme sobre a pronúncia da palavra água em francês permite o estudo da fonologia e fonética da língua francesa. Além de relacionar com a articulação necessária para a produção desse som, temos também a ideia do "biquinho" tão comumente associado com o "falar francês". Enquanto a palavra água em francês - escrita eau e pronunciada fonologicamente /0/ - é representada pela imagem do gato fazendo biquinho, nas outras línguas românicas, como latim, espanhol, português, italiano, catalão e romeno, a palavra é representada por escrito. Conforme Seara, Silva e Nunes (2016), os brasileiros tendem a apresentar mais dificuldade na produção do fonema francês /y/ no início da aprendizagem de FLE, já o fonema /o/ por se tratar de um som semelhante ao Português Brasileiro (PB) não causa dificuldade de produção por parte dos aprendizes brasileiros, entretanto a relação grafia-fonema pode causar estranhamento inicial. Assim, além do meme ironizar a sonoridade da palavra água em francês comparada a outras línguas em que é representada de forma muito parecida, ele facilita a pronúncia e a memorização do fonema da língua francesa /o/ por parte dos aprendizes brasileiros de FLE.

Considerando as conceitualizações e as exemplificações da relação entre memes e ensinoaprendizagem de FLE apresentadas, sentimos a necessidade de elaborar um formulário para conhecer a realidade dessa relação no cenário docente atual: 0 francês on-line na pandemia: memes como ferramenta de ensino-aprendizagem. A metodologia utilizada assim como a análise das respostas dos professores de FLE serão apresentadas a seguir. 


\section{0 perfil do professor de FLE em tempos de likes}

Para contemplar questões levantadas sobre o aumento da procura por aulas remotas de FLE e sobre a necessidade do professor de FLE de se reinventar diante do distanciamento social devido à pandemia de Covid-19, foi realizada uma pesquisa, aplicada entre março e agosto de 2020, com o total de cem participantes-respondentes. A pesquisa contou com a aplicação de um questionário na internet, por meio do aplicativo da Google chamado Google Forms ${ }^{18}$. A escolha desse aplicativo se deu considerando a sua funcionalidade, a gratuidade do serviço, possibilidade de realizar questões de múltiplas escolhas e discursivas, além da elaboração de gráficos a partir das respostas coletadas. 0 suporte teórico para a construção e análise de dados desse questionário foi baseado em Barbetta (2002).

Neste artigo, o perfil do professor de FLE que está trabalhando com 0 ensino on-line é apresentado a partir das respostas e relatos de experiências encontrados no questionário aplicado remotamente, intitulado "O FLE em tempos de likes". A comunidade que participou de nossa pesquisa se enquadra na categoria de professor(a) de FLE que esteja ministrando aulas na modalidade on-line durante o período da pesquisa.

As perguntas realizadas no questionário tiveram como principal objetivo coletar dados que pudessem oferecer informações sobre: i) a faixa etária; ii) o gênero; iii) o nível de escolaridade; iv) as práticas didáticas; v) as plataformas utilizadas para o ensino remoto; vi) as vantagens e as desvantagens do ensino através das telas de computadores e celulares; vii) a presença nas redes sociais e viii) 0 conceito de meme e sua utilização, segundo os respondentes. Além dessas questões, outras perguntas foram formuladas com o objetivo de compreender o impacto da pandemia no ensino on-line de francês.

Os dados analisados revelaram um perfil segundo o qual $51 \%$ dos respondentes são da faixa etária de 26-35 anos; $70 \%$ são do sexo feminino, $29 \%$ do sexo masculino e $1 \%$ outros. Em relação à nacionalidade desse professor, encontramos os seguintes dados: $94 \%$ são de nacionalidade brasileira, sendo $4 \%$ de nacionalidade francesa e $2 \%$ de nacionalidade argentina. Já em relação ao nível de escolaridade, $91 \%$ dos respondentes possuem ou estão em formação na área de Letras-Francês. Há ainda aqueles que possuem pós-graduação em Letras ou em outras áreas $(68,7 \%)$, indicando um perfil de professor preocupado e responsável em sua contínua formação.

Verificamos também que $59 \%$ dos respondentes não lecionava de maneira remota antes do começo da quarentena. Ao analisar esse perfil dos professores de FLE aqui relatado, constatamos que esse resultado vai ao encontro dos números observados no Gráfico 1, retirado da plataforma Google

18 Disponível em: https://www.techtudo.com.br/dicas-e-tutoriais/2018/07/google-forms-o-que-e-e-como-usar-o-app-deformularios-online.ghtml

LínguaTec, Instituto Federal de Educação, Ciência e Tecnologia do Rio Grande do Sul, Bento Gonçalves v. 6, n. 2, p. 53-69, jun. 2021. 
Trends e apresentado na seção 2, em que se evidenciou a crescente procura por aulas de francês online após o início do distanciamento social.

Analisamos, em seguida, as práticas didáticas e as perspectivas desses professores sobre essa modalidade de ensino em ascensão. Tais dados serão analisados e discutidos no tópico a seguir.

\section{Análise e discussão dos dados}

Quando perguntados sobre a preparação de suas aulas, 60\% dos respondentes disseram utilizar um livro didático em conjunto com outros materiais autênticos, adaptando conteúdos, criando exercícios e/ou jogos para seus alunos. Encontramos o percentual de $12 \%$ de professores que afirmaram ter como base um livro didático, tais como Adosphère, AlterEgo, Tout va bien; entretanto, outros (13\%) afirmaram não seguir um livro didático e, sim, preparar a aula de acordo com o perfil e as necessidades do aluno.

Não obstante uma "imposição" do momento, devido ao cenário de pandemia em que nos encontramos, as aulas remotas podem ter inúmeras vantagens, como o conforto de trabalhar de casa, sendo essa a principal vantagem indicada por $73 \%$ dos professores de FLE on-line e, em segundo lugar, conforme relatado, a vantagem do alcance geográfico dessa modalidade de ensino (60\%). Outras duas vantagens que se destacaram foram a maior disponibilidade de horários $(60 \%)$, uma vez que diversos professores se deslocavam no período entre as aulas, e o fator econômico (57\%), já que é possível economizar na passagem de ônibus ou combustível, e nas refeições feitas fora de casa.

Todavia, apesar das várias vantagens encontradas em nossa pesquisa no que diz respeito ao ensino remoto, ainda percebemos certas desvantagens quando comparado ao ensino presencial. 0 problema mais relatado por parte dos respondentes foi a falha na rede de internet ou problemas técnicos (71\%), pois nem todas as regiões do país possuem boas redes de conexão com a internet e, dependendo do clima/tempo, pode-se ter uma conexão bastante instável, a exemplo de quando chove ou venta muito. Outras desvantagens apontadas pelos professores que responderam ao questionário foi a falta de têteà-tête, ou seja, a interação cara a cara entre os alunos e o professor (62\%). Esse dado reflete o caráter fundamental da interação que acontece no processo de ensino-aprendizagem, pois uma aula não é apenas um amontoado de informações a serem despejadas no aluno, mas um momento de troca entre as duas partes e essa interação presencial se mostra um ponto importante nesse processo de ensinoaprendizagem. Além dessa interação social, outro ponto negativo seria a ausência de um espaço de ensino-aprendizagem (57\%), no qual o professor pode explicar no quadro, com o aluno tendo uma visão geral do espaço, onde se formam grupos para atividades como de representação teatral, e no qual o 
professor pode caminhar e utilizar toda a sua linguagem corporal - a forma como caminha, como para em pé, como se senta, como gesticula - nesse processo/ato de ensino-aprendizagem.

Para realizar as suas aulas na modalidade on-line, os professores afirmaram utilizar as plataformas Zoom (31\%), Google Meet (23\%) e Skype (18\%), em sua maioria, embora alguns professores lecionem via WhatsApp (7\%). Os $21 \%$ restantes informaram utilizar plataformas como Messenger, FaceTime, Microsoft Teams, entre outros. Além das plataformas usadas para dar a aula propriamente dita, muitos professores aproveitam as redes sociais para divulgar seu trabalho $(40 \%)$. Alguns usufruem às vezes das redes para divulgação das aulas (28\%), enquanto outros não as utilizam com esse propósito (32\%). Entre as redes mais utilizadas para divulgação de trabalho profissional estão Instagram (46\%) e Facebook (15\%). Esses dados encontrados nos permitem perceber que mesmo após o começo da quarentena no Brasil, e a necessidade de migrar para as plataformas on-line, o popular "boca a boca" ainda é ressaltado como a melhor forma de divulgação segundo alguns respondentes.

Quando questionados sobre o que entendem por meme, 68 respondentes o relacionaram com humor, piada, sarcasmo ou, ainda, o definiram como um "gênero textual para rir". No entanto, é interessante destacar o fato de que 15 respondentes acreditam que o meme é formado por uma imagem acompanhada de um texto, ou seja, consideram-no um gênero híbrido, ou como "textos multimodais". Ainda sobre essa questão, o meme foi descrito por 29 respondentes como uma ferramenta que é criada a partir de fatos e eventos ligados diretamente a uma determinada cultura. Assim dizendo, em sua origem, o meme é contextualizado, mas em seguida pode ser adaptado e utilizado em diversas situações e ambientes. Essas respostas relacionam-se com as discussões teóricas apresentadas na seção 3, em que salientamos o meme enquanto um gênero multimodal, híbrido, humorístico, contendo paródias e fazendo parte do imaginário coletivo de uma determinada comunidade. Sobre a produção e propagação dos memes, 12 respondentes caracterizam o meme como algo que se torna viral; no entanto, 2 respondentes acreditam que atualmente o meme não é necessariamente um conteúdo amplamente divulgado.

Alguns respondentes desenvolveram suas respostas e abordaram a funcionalidade do meme. Nesse sentido, o meme foi apontado não só como uma forma de entretenimento, mas também de reflexão. Além disso, foi visto como uma ferramenta de ensino, a partir da qual questões culturais, políticas, sociais e gramaticais podem ser abordadas em aula. No contexto do ensino, o meme foi considerado como uma forma de diálogo, aproximação e afeto com os alunos. Em relação à utilização de memes em sala de aula, $43 \%$ dos participantes afirmam não os utilizar, enquanto $36 \%$ os utilizam de temps en temps. Já $16 \%$ dos respondentes utilizavam os memes antes de migrar para a modalidade de 
ensino remoto e pretendem continuar usando. É interessante ressaltar que apenas $5 \%$ dos respondentes começaram a utilizar com mais frequência os memes após o início de suas aulas on-line.

Em suma, com essa primeira análise, observamos que tanto as respostas dos participantes como suas perspectivas sobre o ensino remoto e os memes se aproximam de nossas discussões e questões apresentadas neste artigo. Nesse sentido, seguimos para nossas considerações finais.

\section{Considerações finais}

Retomando os questionamentos iniciais realizados neste artigo em relação ao aumento da procura pelo ensino remoto de FLE e a necessidade do professor de FLE de se readaptar diante dessa procura, podemos constatar que os nossos professores-respondentes estão se reinventando no que diz respeito a sua migração à modalidade on-line, pois encontramos um percentual significativo em nossas análises apontando essa movimentação após o início da quarentena no Brasil. Também é possível indicar que esses professores-respondentes estão articulando métodos tradicionais de ensino com novas ferramentas tecnológicas, por exemplo a ferramenta "meme". Entretanto, foi possível observar que os memes não eram utilizados de forma frequente pelos professores-respondentes, pois $43 \%$ responderam não utilizar o meme na modalidade de ensino remoto e apenas $5 \%$ afirmaram utilizar com mais frequência esse gênero após migrar para essa modalidade. Nesse sentido, podemos questionar se a cibercultura está de fato presente no ensino on-line ensinado por esses professores-respondentes.

Sobre o perfil do professor de FLE encontrado em nossa pesquisa, é possível destacar que a grande maioria dos respondentes é de nacionalidade brasileira (94\%) e do sexo feminino (70\%). Também ressaltamos que esses professores-respondentes em sua maioria já são formados ou estão em formação em Letras $(91 \%)$ e possuem pós-graduação $(68,7 \%)$. Nesse sentido podemos considerar um perfil altamente qualificado e comprometido com a sua formação.

No que diz respeito ao meme, observamos que pode ser definido como um gênero textual híbrido, dinâmico e normalmente efêmero, no qual imagem e texto se completam. As mensagens nele escritas são vinculadas a imagens autoexplicativas que fazem parte do imaginário coletivo de comunidades específicas. $O$ meme se utiliza de seu caráter humorístico, por vezes irônico, para criticar o mundo real ao propor uma visão diferente sobre esse mesmo real. Podemos afirmar, portanto, que esse caráter multimodal e humorístico possibilita acessar às questões culturais que transpassam as práticas linguísticas e sociais. Por conseguinte, ele mostra-se uma ferramenta interessante no processo de preparação de aulas on-line de FLE, uma vez que é permitido ao aluno sua autonomia de aprender, ele pode ser autor da criação do meme e tem, assim, um papel ativo na sua aprendizagem. 
Podemos também destacar os benefícios e desafios do ensino pela internet que foram encontrados a partir das respostas da pesquisa. O conforto, a disponibilidade de horário e a questão econômica são citados como benefícios. Entre os desafios, encontramos a falta de ferramentas didáticas, como quadro, de espaço físico de aprendizagem e da linguagem corporal, além dos problemas técnicos, como a instabilidade da internet.

Por fim, a presente pesquisa possibilitou uma reflexão sobre o ensino on-line de FLE que nos permite ter uma visão mais aprofundada sobre essa realidade. Passar do ensino presencial para o ensino remoto não é uma simples adaptação, mas uma recriação que permite aos professores de FLE seguirem por caminhos diversos. A partir das respostas apresentadas no formulário, foi possível observar que há quem siga os livros didáticos tal qual no presencial, mas também quem busque se adaptar à cibercultura, tanto no ensino como nos métodos de ensino-aprendizagem, aqui especificamente tratando da utilização dos memes. Ainda considerando os resultados da pesquisa, verificamos que esse artigo é apenas o ponto de partida de uma reflexão ainda mais profunda, tratando-se do perfil do professor, do ensino online de FLE e da ferramenta de ensino meme.

\section{Referências}

AGUIAR, Ione. De novo?! Acredite, já temos uma Terceira Guerra Memeal. HuffPost Brasil, 2016. Disponível em: https://www.huffpostbrasil.com/2016/06/18/de-novo-acredite-ja-temos-uma-terceiraguerra-memeal_n_10548908.html. Acesso em: 30 jul. 2020.

APRÍGIO, Marcelo. Em tempos de coronavírus, escolas levam cursos de idioma para dentro de casa. Uol, 2020. Disponível em: https://jc.ne10.uol.com.br/economia/2020/05/5607950-em-tempos-decoronavirus--escolas-levam-cursos-de-idioma-para-dentro-de-casa.html. Acesso em: 28 jul. 2020.

ARAÚJJ, J. X. Memes: A linguagem da diversão na Internet. Monografia (Graduação em Comunicação Social/Jornalismo) - Universidade Federal do Rio de Janeiro, Escola de Comunicação - ECO. Rio de Janeiro, 2012.

ARRUDA, Larissa. Um breve panorama histórico do ensino de FLE no Brasil: origens, contatos culturais e evoluções políticas. Cadernos Neolatinos, 2016.

BARBETTA, Pedro Alberto. Estatística aplicada às Ciências Sociais. 5. ed. Florianópolis: Ed. da UFSC, 2002.

BARRETO, K. H. Os memes e as interações sociais na Internet: uma interface entre e estudos de face. 2015. Tese (Doutorado em Linguística) - Universidade Federal do Juiz de Fora, Juiz de Fora, 2015. 
CARDOSO, J. S.; ALCANTARA, A. C. B.; MATTA, A. B. S. Memes no aprendizado de línguas: uma prática multiletrada na formação docente para a justiça social. Periferia (Duque de Caxias), v. 11, p. 5472, 2019.

FELLET, R. Ensino on-line de idiomas é opção durante período de isolamento social. UFJF Notícias. Publicado em 27 mar. 2020. Disponível em: https://www2.ufff.br/noticias/2020/03/27/ensino-on-line-deidiomas-e-opcao-durante-periodo-de-isolamento-sociall. Acesso em: 10 ago. 2020.

KONFU. Latin: Aqua; Spanish: agua; Portuguese: água; Italian: acqua; Catalan: aígua; Romanian: apã; French:: 23 set. Twitter: @xxxkonfusion. Perfil temporariamente suspenso. Acesso em: 05 ago. 2020.

LÉVY, Pierre. Cibercultura. Tradução: Carlos Irineu da Costa. São Paulo: Editora 34, 2009.

LUCENA, H. M. A.; PONTES, V. M. A. O meme no ensino de língua portuguesa do ensino médio. tics \& ead em foco, v. 4, p. 95-109, 2018.

MOREIRA, Isabela. Espanha começa a Terceira Guerra Memeal. Galileu, 2016. Disponível em: https://revistagalileu.globo.com/blogs/buzz/noticia/2016/06/espanha-comeca-terceira-guerramemeal.html. Acesso em: 30 jul. 2020.

ORGANISATION INTERNATIONALE DE LA FRANCOPHONIE. La langue française dans le monde (2015-2018). Paris: Gallimard, 2019.

Saiu! Katy Perry divulga clipe estrelado por Gretchen. R7, 2019. Disponível em: https://entretenimento.r7.com/famosos-e-tv/saiu-katy-perry-divulga-clipe-estrelado-por-gretchen$\underline{06102019}$. Acesso em: 28 jul. 2020.

SEARA, I. C.; SILVA, S. F.; NUNES, V. G. Les Lusophones. In: DETEY, S., RACINE, I., KAEAGUCHI, Y. \& EYCHENNE, J. (org.). La prononciation du français dans le monde: du natif à l'apprenant. Paris: CLE, 2016, v. 1, p. 1-8.

SEIMOHA, Karine. Criatividade dos brasileiros eleva o País ao posto de potência global de Memes. IG, 2017. Disponível em: https://gente.ig.com.br/cultura/2017-07-25/memes-brasil-grande-potencia.html. Acesso em: 28 jul. 2020.

SILVA, Rafael Rodrigues da. Brasil é o segundo país do mundo a passar mais tempo na internet. Canaltech, 2019. Disponível em: https://canaltech.com.br/internet/brasil-e-o-segundo-pais-do-mundo-apassar-mais-tempo-na-internet-131925. Acesso em: 14 jun. 2020.

SILVA, Victor Hugo. Exclusivo: Akamai vê uso da internet crescer $112 \%$ no Brasil durante pandemia. Tecnoblog, 2020. Disponível em: https://tecnoblog.net/344896/exclusivo-akamai-ve-uso-de-internetcrescer-112-no-brasil-durante-pandemial. Acesso em: 22 jun. 2020.

SOUZA E SOUZA, Liz Sandra. Colégio Pedro Il: Um Lugar de Memória do Ensino de Línguas no Brasil. Revista HELB, ano 6, n. 6. ISSN 1981 6677. Disponível em: http://www.helb.org.br/index.php/revistahelb/ano-6-no-6-12012/201-colegio-pedro-ii-um-lugar-de-memoria-do-ensino-de-linguas-no-brasil. Acesso em: 18 maio 2014. 
TREVISOL, M.; MACIEL, A. P. Perspectivas educacionais na era da informação: a utilização das novas tecnologias midiáticas como ferramentas pedagógicas. Chapecó: UNOESC, 2011.

WOOSHING, Ethereal. J'apprends que maintenant qu'il y a une page de memes brésiliens qui s'appelle "Je suis fan des français parce que dès qu'il se passe quelque chose ils brûlent des voitures" qui a plus de 90000 like. 10 de Dezembro 2018, 21:53 pm. Twitter: @etherealwooshng. Acesso em: 20 jul. 2020.

XAVIER, A. D.; SOUZA, E. L. M.; OLIVEIRA, S. B. A construção de memes como ferramenta de ensino da língua inglesa. Periferia (Duque de Caxias), v. 11, p. 140-161, 2019.

Data de submissão: 14/03/2021. Data de aprovação: 05/05/2021. 